\title{
Is University Nursing Education in Canada Taking the Lead in a World Focused on Sustainable Development? / La formation universitaire au Canada est-elle à l'avant-plan dans un monde centré sur le développment durable?
}

\author{
Ginger Sullivan \\ University of Alberta, ginger.sullivan@ualberta.ca \\ Jennifer Bell Ms \\ University of Alberta, jbell2@ualberta.ca \\ Mona Haimour \\ Macewan University, haimourm@macewan.ca \\ Solina Richter Dr. \\ University of Alberta, mrichter@ualberta.ca
}

Follow this and additional works at: https://qane-afi.casn.ca/journal

Part of the Nursing Administration Commons, and the Other Nursing Commons

\section{Recommended Citation}

Sullivan, Ginger; Bell, Jennifer Ms; Haimour, Mona; and Richter, Solina Dr. (2019) "Is University Nursing Education in Canada Taking the Lead in a World Focused on Sustainable Development? / La formation universitaire au Canada estelle à l'avant-plan dans un monde centré sur le développment durable?," Quality Advancement in Nursing Education Avancées en formation infirmière: Vol. 5: Iss. 2, Article 2.

DOI: https://doi.org/10.17483/2368-6669.1177

This Article is brought to you for free and open access by Quality Advancement in Nursing Education - Avancées en formation infirmière. It has been accepted for inclusion in Quality Advancement in Nursing Education - Avancées en formation infirmière by an authorized editor of Quality Advancement in Nursing Education - Avancées en formation infirmière. 
Is University Nursing Education in Canada Taking the Lead in a World Focused on Sustainable Development? / La formation universitaire au Canada est-elle à l'avant-plan dans un monde centré sur le développment durable?

\section{Cover Page Footnote}

Acknowledgements The authors identify no conflict of interest. The authors are grateful for the support from Jean Chaw-Kant during the final stages of the manuscript writing and submission. 


\section{Introduction}

The world is becoming increasingly complex. There is a rising tide of inequity within and among nations, influenced by increasing political strife and extremism; an expanding burden of communicable and non-communicable disease; and escalating malnutrition. These challenges, among others, overlap on a backdrop of continual degradation of our planet. As the largest number of health care providers worldwide, nurses have a significant stake in the future of our world and the health of our populations. These complexities require nurse educators to reflect and examine how our educational institutions and curricula prepare future generations of nurses to take leadership in addressing these critical global issues.

Around the globe, in the vast majority of nations, nursing and nursing education has long viewed global health as part of their professional mandates, but does this directive translate into nurses taking action (Benton \& Shaffer, 2016; Canadian Nurses Association [CNA], 2009; International Council of Nurses [ICN], 2015). Are nurses at the forefront of developing, implementing, monitoring, and evaluating global health interventions? Do our nursing education programs demonstrate effectiveness in preparing students to provide guidance for noncommunicable disease prevention, chronic diseases, disaster preparedness, and environmental health? Are nursing students able to advocate and promote access to quality health care in all settings? These are pertinent questions to consider.

In Canada, global health has been a priority for nurses and nursing education. The Canadian Nurses Association's (CNA, 2009) position statement on global health and equity highlights that "health is a global issue and global health ... is a fundamental human right" (p. 1). In addition, the CNA recognizes that global health is not a standalone concept that is exclusively connected to research, education, or clinical practice, but rather a concept that requires contributions from all nursing stakeholders with a priority focus on the implementation of solutions (CNA, 2009). In contrast, a recent report released by the Canadian Nursing Students' Association (CNSA, 2016) provides a critical analysis of the current state of global health nursing education in Canada. The report highlights that although 11 out of the 13 provinces and territories explicitly named global health as a required entry-to-practice competency, there is a gap in translating nursing students' knowledge of global health into action by students and practising nurses (CNSA, 2016). University nursing programs have a responsibility to ensure that knowledge of global health and global health competencies are included in curricula (CNSA, 2017; Clarke, Raffray, Hendricks, \& Gagnon, 2016). Recent work has attempted to identify the global health competencies necessary for nursing curricula (Clarke et al., 2016), and other work has evaluated competencies identified for public health nursing and how they relate to global health initiatives (Joyce et al., 2017). Without clear learning outcomes and well-structured global health content, the gap between what the CNA advocates for and what occurs in education and practice will only widen.

In September 2015, the 193 head member states of the United Nations General Assembly ratified the Sustainable Development Goals (SDGs): 17 goals and 169 associated targets to end poverty, protect the environment, and ensure health and well-being for all (United Nations, 2015). This ratification was followed by the release of 230 goal indicators intended to monitor the global progress of achieving the SDGs (United Nations, 2015; United Nations Statistics Division, 2017). These goals will guide the world's development agenda until 2030 and offer new ways of examining poverty, promoting just societies, and guiding standards related to health and well-being. This landmark agenda gives rise to a new era in nursing education by providing 
international guidelines for nursing practice and influencing how we educate nurses. Canadian universities offering nursing education programs are uniquely positioned to integrate the SDGs into nursing curricula, research, leadership, and nursing practice. Until now, little has been done to understand how academic institutions, and in particular nursing faculties and schools, propose to achieve these 17 goals. Nurses are the single largest group of health care professionals in the world and arguably the profession with the highest potential impact on the health of people; it is critical to articulate our educational responsibilities in attaining the SDGs (ICN, 2017; Kavey, 2009).

Considering these claims, our research team was interested in how the guiding documents at Canadian universities addressed the SDGs, specifically how nursing faculties and schools incorporated this global mandate into their strategic plans (SPs). SPs were selected for analysis as these documents usually serve as the foundation for the vision and mission of an organization. The purpose of this paper is to share findings from a study that examined Canada's largest nursing faculties'/schools' SPs, written in English, and to discuss how these mandates aligned with the achievement of the 17 SDGs.

\section{Methodology}

Many research projects are initiated based on informal discussions and musings about the why or how of things. In our case, initial discussions and questioning of how Canadian nursing programs incorporated the SDGs into their curricula led to one guiding research question: how are the SDGs addressed in the top 10 Canadian Faculty of Nursing's or School of Nursing's strategic plans? To answer this question, we conducted a summative content analysis of SPs for the top 10 university nursing programs in Canada.

Specifically, we examined how the SDGs were addressed in these plans. Our study was descriptive in nature and used a qualitative content analysis as the design. Qualitative content analysis as a research method is a systematic means of describing phenomena. The method has also been used to analyze documents and allows researchers to enhance their understanding of content and distil words and phrases into fewer content-related categories. Categories of words and phrases are then sorted to identify patterns and theorized to create conceptual meaning (Elo \& Kyngas, 2007; Krippendorff, 1980; Downe-Wamboldt, 1992; Sandelowski, 1995). There are several different content analysis methods ranging from intuitive/impressionistic analysis to strict textual analysis (Polit \& Beck, 2017). The method best suited to answer our research question was a summative content analysis. The summative method begins with a preliminary organizing framework, and from this framework key words/concepts are identified and used to guide the analysis of the narrative data. In our study, the 17 SDGs and their corresponding targets were used to develop the preliminary coding framework. Details regarding the process of developing the framework are found in Figure 1. We chose to examine written text via strategic plans and relied on the researchers' interpretation. This method was chosen because SPs form and reflect a aculty's mandate, mission, and vision, as they are intended to guide all decision making, including research, teaching, and curriculum priorities. 
Figure 1

Process of developing the coding framework
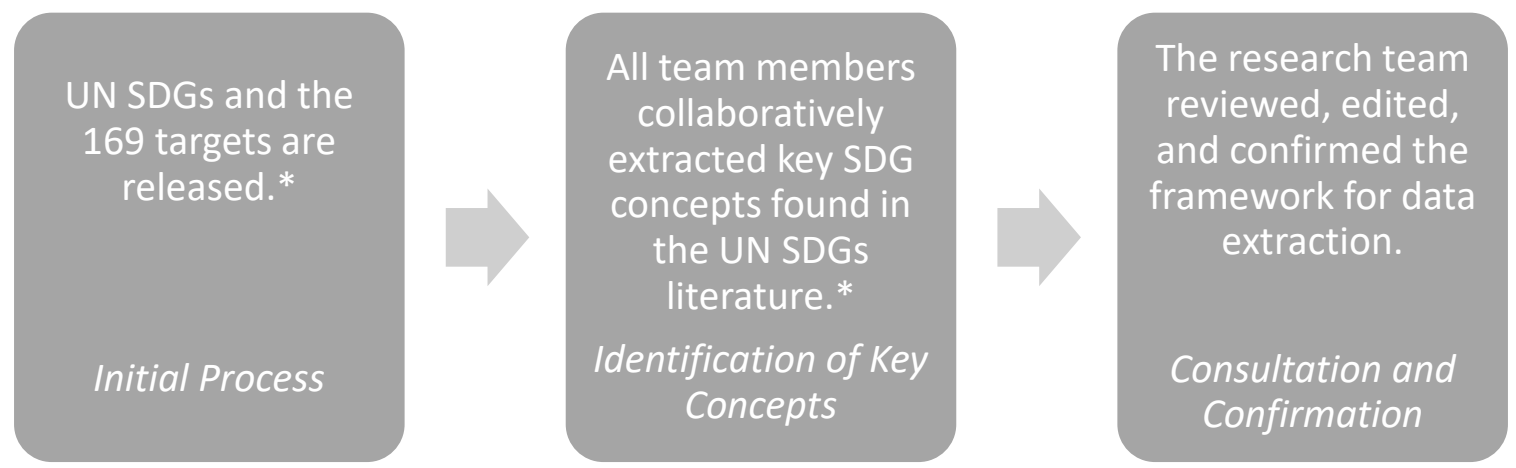

* United Nations Statistics Division. (2017). SDGs Indicators: Global indicator framework for the Sustainable Development Goals and targets of the 2030 Agenda for Sustainable Development. Retrieved from https://unstats.un.org/sdgs/indicators/indicators-list

We chose SPs from the top 10 nursing university programs in Canada according to the QS World University Ranking by Subject 2016 (QS Top Universities, n.d.). The QS ranking system is recognized as a qualified peer-reviewed system and allows for the application of specific search criteria, such as faculty of nursing/school of nursing. In Canada, nursing education programs are evaluated and accredited based on a specific set of standards for both the educational unit and the nursing education program.

Using the QS system provided an objective method to determine which professional nursing education programs would be included in the analysis. As with any ranking system, there are criticisms (Olcay \& Bulu, 2017); however, we felt that the benefits of having a specific list of ranked nursing faculties or schools was valuable for this project. The Maclean's list of rankings was considered; however, methodological issues in that ranking system have been identified by academics (Cramer et al., 2016). The Times Higher Education list was also considered; however, that ranking does not allow for a search specific to nursing.

Using the QS rankings, we retrieved the top 10 Canadian Faculty of Nursing's, School of Nursing's, and Departments of Nursing's SPs from their websites. All SPs were public documents and thus no ethics committee approval was required.

Nine plans were retrieved. One plan was omitted because we were unable to obtain an English copy of the required document. It is important to note that several of the SPs included disciplines other than nursing. For example, the School of Nursing at the University of Ottawa's strategic plan is included in the Faculty of Health Sciences' strategic plan; at McGill University, the School of Nursing's strategic plan is included under the Faculty of Medicine. See Table 1 for information on the universities, their rankings, and where the nursing academia was housed at each institution. 
Table 1

Institutions included in analysis

These are listed according to rankings by the QS World University Ranking by Subject 2016.

University $\quad$ Faculty or School Included

\begin{tabular}{|c|c|c|}
\hline University of Toronto & $\begin{array}{l}\text { Lawrence S. Bloomberg Faculty of } \\
\text { Nursing }\end{array}$ & Yes \\
\hline University of Alberta & Faculty of Nursing & Yes \\
\hline $\begin{array}{l}\text { University of British } \\
\text { Columbia }\end{array}$ & School of Nursing & Yes \\
\hline $\begin{array}{l}\text { University of Western } \\
\text { Ontario }\end{array}$ & $\begin{array}{l}\text { Arthur Labatt Family School of } \\
\text { Nursing (housed under Western } \\
\text { Health Sciences) }\end{array}$ & Yes \\
\hline McGill University & $\begin{array}{l}\text { Ingram School of Nursing (housed in } \\
\text { the Faculty of Medicine) }\end{array}$ & Yes \\
\hline McMaster University & $\begin{array}{l}\text { School of Nursing (housed under the } \\
\text { Faculty of Health Sciences) }\end{array}$ & Yes \\
\hline $\begin{array}{l}\text { Queen's University at } \\
\text { Kingston }\end{array}$ & $\begin{array}{l}\text { School of Nursing (housed under the } \\
\text { Faculty of Health Sciences) }\end{array}$ & Yes \\
\hline Université de Montréal & Faculty of Nursing & $\begin{array}{l}\text { No. Unable to obtain } \\
\text { English-language } \\
\text { documents for analysis. }\end{array}$ \\
\hline University of Calgary & Faculty of Nursing & Yes \\
\hline University of Ottawa & $\begin{array}{l}\text { School of Nursing (housed under the } \\
\text { Faculty of Health Sciences) }\end{array}$ & Yes \\
\hline
\end{tabular}

The project was completed in four phases.

Phase One: Extracting and summarizing data. During this phase, we conducted a summative content analysis using a coding framework collaboratively developed by the research team members. The framework contained key concepts and exact language found in the 17 SDGs and their corresponding targets (see Table 2 for the framework details). The nine strategic plans were divided among team members. For each original SP, data extraction was conducted by two independent reviewers using multiple readings and noting general interpretations of how the SDGs were represented in each document. Key SDG concepts were extracted and collated into a table (Table 2). To confirm interrater reliability, each of the four team members conducted a data extraction exercise using SDG 1, no poverty, and an exemplar Faculty of Nursing SP. This initial interrater reliability demonstrated that team members' conclusions were similar and that their independent data extraction results aligned. The research team reviewed, edited, and confirmed 
the framework for further data extraction. After an independent analysis of all the nursing specific SPs, the second phase was initiated.

Table 2

Framework used for data extraction

Sustainable Development Key Language and Concepts

Goal

Goal 1. End poverty in all its forms everywhere

Goal 2. End hunger, achieve food security and improved nutrition, and promote sustainable agriculture

Goal 3. Ensure healthy lives and promote well-being for all at all ages

Goal 4. Ensure inclusive and equitable quality education and promote lifelong learning opportunities for all

Goal 5. Achieve gender equality and empower all women and girls

Goal 6. Ensure availability and sustainable management of water and sanitation for all

Goal 7. Ensure access to affordable, reliable, sustainable, and modern energy for all

Goal 8. Promote sustained, inclusive, and sustainable economic growth; full and productive employment; and decent work for all
Poverty, extreme poverty, poverty eradication, economic development

Zero hunger, end hunger, malnutrition, sustainable agriculture, food security

Maternal mortality, neonatal mortality, communicable diseases, non-communicable diseases, universal health care (coverage), good health, personal well-being(ness), risk-reduction strategies

Quality education, equitable education, affordable education, literacy, inclusive education facilities, qualified teachers

Gender discrimination, gender inequality, equal rights, exploitation, forced marriage, female genital mutilation, reproductive health, reproductive rights

Clean water, clean sanitation, adequate drinking water, improve water quality, water scarcity, water efficiency, water resource management

Affordable energy, modern energy, reliable energy, renewable energy, energy efficiency, clean energy, clean energy research, energy infrastructure

Sustainable economic growth, decent work, economic diversity, technological upgrading, development-oriented policies, sustainable consumption, sustainable production, productive employment, worker diversity, youth employment, eradication of forced labour (labor), human trafficking and modern slavery, child labour (labor), child soldiers, protect labour (labor) rights, safe work environments, labour (labor) rights protection, sustainable tourism, access to financial services, Aid for Trade, 


\section{Goal 9. Build resilient infrastructure, promote inclusive and sustainable industrialization, and foster innovation}

Goal 10. Reduce inequality within and among countries

Goal 11. Make cities and human settlements inclusive, safe, resilient, and sustainable

Goal 12. Ensure sustainable consumption and production patterns

Goal 13. Take urgent action to combat climate change and its impacts

Goal 14. Conserve and sustainably use the oceans, seas, and marine resources for sustainable development

Goal 15. Protect, restore, and promote sustainable use of terrestrial ecosystems; sustainably manage forests; combat desertification; and halt and reverse land

\section{Global Jobs Pact}

Industry, innovative infrastructure, inclusive industrialization, sustainable industrialization, access to financial services, research and development, technology capacity, research spending, sustainable infrastructure, access to communication technology, Internet access

Income growth, social inclusion, economic inclusion, political inclusion, inequalities of outcome, equal opportunity, social protection policies, regulate global financial markets, economic representation of developing countries, migration policy, differential treatment of developing countries, migrant remittances

Sustainable cities, sustainable communities, sustainable buildings, access to safe and affordable housing, transportation systems, public transportation improvement, inclusive urbanization, sustainable urbanization, cultural heritage, natural heritage, economic loss from disasters, environmental impact of cities (urban centres), public spaces, Sendai Framework for Disaster Risk Reduction 2015-2030.

Responsible consumption, responsible production, sustainable use of natural resources, global food loss, environmental management of chemicals, waste management, (environmental) sustainability, sustainable tourism

United Nations Framework Convention on Climate Change, adaptive capacity for climate change, integrate national policy for climate change, education on climate change, Green Climate Fund

Reduce marine pollution, management of marine and coastal ecosystems, protection of marine and coastal ecosystems, healthy and productive oceans, ocean acidification, sustainable fishing practices, coastal and marine are conservation, fishing regulations, sustainable aquaculture, sustainable tourism, Intergovernmental Oceanographic Commission Criteria and Guidelines on the Transfer of Marine Technology, artisanal fishers

Sustainable forests, sustainable freshwater ecosystems, land restoration, combat desertification, conserve mountain ecosystems, halt the loss of biodiversity, protect and prevent the extinction of threatened species, sharing genetic resources, end poaching and trafficking of protected species, stop invasive alien species, integration of ecosystem and biodiversity plans, 
degradation and halt

biodiversity loss

Goal 16. Promote peaceful and inclusive societies for sustainable development, provide access to justice for all, and build effective, accountable, and inclusive institutions at all levels

Goal 17. Strengthen the means of implementation and revitalize the global partnership for sustainable development financial resource allocation for environmental sustainability

Reduce violence and related death rates, end abuse, exploitation, trafficking, end violence and torture of children, promote rule of law, equal access to justice, reduce illicit financial and arms flows, combat organized crime, reduce corruption and bribery, inclusive decision making, participation of developing countries in the institutions of global governance, legal identity for all, public access to information, capacity building, nondiscriminatory laws.

Domestic resource mobilization, domestic revenue collection for developing countries, implementation of development assistance commitments, long-term debt sustainability, reduce debt stress for developing countries, international cooperation for technology sharing, focus on environmentally stable technologies, improve technology, science and information sharing capacities, capacity building in developing countries, equitable multilateral trading system, Doha Development Agenda, increase the exports of developing countries, global macroeconomic stability, policy coherence for sustainable development, global partnership for sustainable development, promote effective public, public-private and civil society partnerships, availability of reliable and high-quality data

Phase Two: Reviewing data. This phase consisted of team members meeting to review the preliminary results. Disagreements around extraction and interpretations of original data were addressed among all four team members using a consensus approach. The consensus approach the team used to address inconsistencies included general discussion, explanation, debate, and agreement. For each SP included in the analysis, two team members independently analyzed each document and then met to discuss results, using the method described. If they were unable to agree, the disagreement was presented at the next team meeting with all four researchers present. The two researchers who were not involved in the initial analysis listened to the debate and offered their opinion. Ultimately, the team was able to come to general agreements about all of the identified conflicts.

Phase Three: Displaying the data. In this phase, data were organized and displayed in a spreadsheet, which helped in integrating concepts, identifying patterns between data, and further exploring conclusions.

Phase Four: Drawing and verifying conclusions. This phase consisted of a final analysis of all the nine SPs to determine (1) the most frequent SDGs addressed in the overall strategic plans, (2) SDGs that were not addressed in the plans, and (3) any unique findings. Team members discussed recommendations for nursing education moving forward. 


\section{Findings}

Of the QS rankings, nine SPs were analyzed for content related to the SDGs; one of the top 10 nursing school's SP was not available in English. Of these plans, six nursing faculties and schools had their own nursing specific plans, while three faculties/schools shared strategic plans with other health sciences facilities (see Table 1).

The top three most commonly referenced SDGs were Goal 3, ensure healthy lives and promote well-being for all and all ages; Goal 4, ensure inclusive and equitable quality education and promote lifelong learning opportunities for all; and Goal 17, strengthen the means of implementation and revitalize the global partnership for sustainable development (see Table 3 for further details of SDG frequency). The most commonly identified SDG (Goal 3) tended to specifically focus its content on the health of students, faculty, and staff rather than on the health of populations or the broader public. A limited number of plans mentioned health in relation to health equity, which is a core focus of SDG 3 . The three non-nursing specific strategic plans tended to touch on a wider range of SGDs, particularly Goal 2, zero hunger; and Goal 16, peaceful and just institutions. Notably, all the plans highlighted the need for quality higher education and articulated the necessity of engaging with local and international stakeholders to achieve their mission.

Table 3

Frequency of Sustainable Development Goals referenced in strategic plans

Sustainable Development Goal $\quad$ Number of SPs References (total 9 SPs)

SDG $3,4,17$

SDG 10

SDG $2,5,16$

SDG $1,6,7,9,11,12,13,14$

SDG 8,15

A key finding was that almost all of the nine SPs referred to Indigenous health and emphasized the need to address the social, political, and health inequities that affect Indigenous peoples in Canada. Regrettably, the SDGs do not specifically reference Indigeneity nor are they specified in their corresponding targets. This is perhaps a shortcoming of the goals rather than the SPs.

\section{Discussion and Recommendations}

Nurses are the primary providers of health care in all settings around the globe; 20.7 million nurses and midwives practise in settings worldwide. The previous director general of the World Health Organization (WHO), Margaret Chan, has stated that nurses have been underused for global health practice, and occasionally, in the global health arena, the profession has been named the "sleeping giant," an untapped resource, especially in the past Millennium Development Goal era (Benton \& Shaffer, 2016). In a recent review by Benton and Shaffer 
(2016), the authors highlight that during the Millennium Development Goal era nursing was slow to address opportunities, and the profession's contributions were often restricted to goals that had specific health indications. Many Canadian nursing educators have voiced their commitment to creating and sustaining opportunities to advance the sustainable development agenda through education, mentorship, research and practice; however, our analysis of the nursing SPs seem to indicate that the SDGs are being passively considered rather than intentionally integrated into academic institutions. In Canada, we have nearly 300,000 professional nurses and thus have significant potential to contribute to the actualization of the SDGs. However, if nursing scholars, researchers, and educators are neither aware of nor comfortable with the SDG mandates, it will be difficult to implement this agenda by 2030. This is a new era, and nurse educators are uniquely positioned to engage with others to address the ambitious SDG agenda. In line with the International Council of Nurses' (ICN) recent publication Nurses-A Voice to Lead: Achieving the SDGs, nursing educators must ensure that we use the language of the SDGs and translate this language into our SPs, policies, curricula, and everyday interactions with our students (ICN, 2017). We do not want to be left behind, and we are not asleep; we must be intentional about how to incorporate the SGDs into our SPs, as this serves as the basis for moving from intention to action.

Our analysis demonstrated that several key SGDs and associated targets are not explicitly identified by many of the nursing specific strategic plans but are potential areas in which nursing education could make a significant contribution, including no poverty, no hunger, gender equality, and climate action. We have four specific recommendations.

First, we recommend that nursing higher education institutions should create and enable environments conducive to skill and knowledge development of the SDG agenda. To do so, the SGDs and their tenets need to be purposely incorporated into nursing curricula, for example, by including them as aims and scope of a course. Some aspects of nursing curricula may in fact include the tenets of the SDGs but usually not explicitly so. Including them as specific aims will contribute to skill and knowledge development around the SDGs.

Second, nursing education must be clear and intentional about our commitment towards attaining the SDG targets. This commitment to the SDGs could manifest as not only including them in SPs but also prioritizing them in faculty mandates and, as mentioned above, as nursing competencies. In doing so, nursing education could ultimately develop a robust infrastructure for knowledge development, mobilization, sharing, and integration. The use of monitoring and evaluation processes should be part of the action plan to ensure these commitments are being met.

Third, nurses and nursing educators must have a common understanding of the current global health landscape, along with an understanding of the SDGs agenda at all levels - global, regional, national, and local. This can be achieved through investing in professional dialogue, networking, and capitalizing on learning opportunities using information and communication technology. To do so, national and international leadership is fundamental in achieving this recommendation. At present, the CNA does not have a position statement or policy document addressing nursing's commitment to the SGDs, despite a long history of engaging with international partners and supporting global work. The most recent position statement on global health and equity (CNA, 2009) references the Millennium Development Goals. This gap in national leadership must be addressed to support nurses and nursing educators in establishing 
foundational knowledge of the SDGs. As expected, the ICN has released a joint action plan outlining a strategy to address the SDGs (World Health Organization, 2018).

Finally, we recommend that the discipline of nursing capitalize on our leadership in influencing other disciplines to attend to the requirements set out by the SDGs. Having the discipline of nursing take leadership in addressing the SDGs has been echoed by a variety of health care leaders, including the former chief executive officer of the ICN, Frances Hughes (2017). Sometimes calls for leadership in nursing can sound hollow, but there are tangible examples of nursing taking leadership roles in addressing the SDGs; the ICN has developed a website to highlight global case studies in which nurses are leading the way in devoting efforts to address the SDGs. Therefore, nurses and nursing educators must value their role with respect to achieving the SDGs, by building on existing knowledge and evidence that facilitate the development of innovative interventions (i.e., teaching methodologies) that generate high-impact and sustainable outcomes.

\section{Limitations}

This work has four limitations. First, strategic plans rarely provide background material or complete information about a faculty's teaching, learning, and engagement activities. For example, many of the plans used flowcharts to present statistical data with minimal or no contextual information of how they contributed to the development of the SPs. This lack of information compelled us to infer meanings in some cases. Second, institutions often use diverse and non-standard formats in preparing and presenting their SPs. Academic institutions tended to have their own specific and unique method of producing these plans, making it difficult to systematically analyze the documents. Third, a significant limitation of our study relates to timing. Timeframes for the plans widely varied and were institution specific. In some cases, some of the SPs included in the analysis were published before the SDGs were released in January 2016. Fourth, as with any research, interpretation bias could have influenced the findings. In this particular research, the team attempted to mitigate this occurrence by analyzing documents individually and then meeting to agree or disagree on findings. We also addressed this by cross confirming each other's work at various points in the process and by having in depth discussions about how the findings were derived. It will be important to conduct a follow-up analysis on how nursing faculties and schools incorporate the SDG agenda into their strategic plans. This process will aid in identifying progress and remaining gaps.

\section{Conclusion}

Our analysis of how the United Nations SDGs are represented in the top 10 Canadian university nursing programs' strategic plans provided valuable information for the future directions of nursing education in Canada. Although nearly all university nursing programs in Canada have identified global health as a key component in their educational programs, there is a clear disconnect as to how this mandate translates into overall institutional strategic plans and thus influences students' learning outcomes and practice. With the establishment of the new SDG agenda, nurses and nursing educators, researchers, and clinicians are well situated to advocate for and participate in shaping this new era in global health. Nursing education programs could use this open window as an opportunity to educationally invest and to identify clear program competencies focused on SDG targets, which will in turn create a cadre of knowledgeable nurses who are at the forefront of improving health and health services for all peoples in all settings around the world. In this new era of a world focused on sustainable 
development, we suggest that this not be a missed opportunity, as nurses are well positioned to lead the implementation of this global mandate. 


\section{References}

Benton, D., \& Shaffer, F. (2016). How the nursing profession can contribute to the Sustainable Development Goals. Nursing Management, 23(7), 29-34. https://doi.org/10.7748/nm.2016.e1534

Canadian Nurses Association. (2009). Global health and equity [Position statement]. Retrieved from https://www.cna-aiic.ca/ /media/cna/page-content/pdfen/ps106_global_health_equity_aug_2009_e.pdf

Canadian Nursing Students' Association [CNSA]. (2017). Global Health in Undergraduate Nursing Education- An Essential Component [Position statement]. Retrieved from http://cnsa.ca/wp-content/uploads/2017/02/Global-Health-in-Undergraduate-NursingEducation-An-Essential-Component.pdf

Clark, M., Raffray, M., Hendricks, K., \& Gagnon, A. J. (2016). Global and public health core competencies for nursing education: A systematic review of essential competencies. Nurse Education Today, 40, 173-180. https://doi.org/10.1016/j.nedt.2016.02.026

Cramer, K. M., Page, S., Burrows, V., Lamoureux, C., Mackay, S., Pedri, V., \& Pschibul, R. (2016). The marketing of Canadian university rankings: A misadventure now 24 years old. Collected Essays on Learning and Teaching, 9, 227-236. https://doi.org/10.22329/celt.v9i0.4434

Downe-Wamboldt, B. (1992) Content analysis: method, applications and issues. Health Care for Women International, 13, 313-321.

Elo, S., \& Kyngas, H. (2007). The qualitative content analysis process. Journal of Advanced Nursing, 62(1), 107-115. https://doi.org/10.1111/j.1365-2648.2007.04569.x

Hughes, F. (2017). Nurses: a voice to lead-Achieving the Sustainable Development Goals. International Nursing Review, 64(1), 4. https://doi.org/10.1111/inr.12354

International Council of Nurses. (2015). ICN mission, vision and strategic plan. Retrieved from http://www.icn.ch/who-we-are/our-mission-strategic-intent-core-values-and-priorities/

International Council of Nurses. (2017). Nurses: A voice to lead-Achieving the SDGs. Retrieved from https://www.icnvoicetolead.com/wpcontent/uploads/2017/04/ICN_AVoiceToLead_guidancePack-9.pdf

Joyce, B., Brown-Schott, N., Hicks, V., Johnson, R., Harmon, M., \& Pilling, L. (2017). Original research: The global health nursing imperative: Using competency-based analysis to strengthen accountability for population focused practice, education, and research. Annals of Global Health, 83(3-4), 641-653. https://doi.org/10.1016/j.aogh.2017.05.006

Kavey, R. (2009). Leadership commitments to improve value in healthcare: Finding common ground: Workshop summary. Institute of Medicine (US) Roundtable on Evidence-Based Medicine. Washington, DC: National Academies Press. Retrieved from National Center for Biotechnology Information website: https://www.ncbi.nlm.nih.gov/books/NBK52843/

Krippendorff, K. (1980). Content analysis: An introduction to its methodology. Newbury Park, CA: Sage Publications. 
Olcay, G. A., \& Bulu, M. (2017). Is measuring the knowledge creation of universities possible?: A review of university rankings. Technological Forecasting \& Social Change, 123, 153160. https://doi.org/10.1016/j.techfore.2016.03.029

Polit, D. F., \& Beck, C. T. (Eds.). (2017). Nursing research: Generating and assessing evidence for nursing practice (10th ed.). Philadelphia, PA: Wolters Kluwer/Lippincott Williams \& Wilkins.

QS Top Universities. (n.d.). QS world university rankings by subject 2016-Nursing. Retrieved from https://www.topuniversities.com/university-rankings/university-subjectrankings/2016/nursing

Sandelowski, M. (1995) Qualitative analysis: what it is and how to begin? Research in Nursing \& Health, 18, 371-375.

United Nations. (2015). Transforming our world: The 2030 agenda for sustainable development. Retrieved from http://www.un.org/ga/search/view_doc.asp?symbol=A/RES/70/1\&referer=/english/\&Lan $\mathrm{g}=\mathrm{E}$

United Nations Statistics Division. (2017). SDGs indicators: Global indicator framework for the Sustainable Development Goals and targets of the 2030 agenda for sustainable development. Retrieved from https://unstats.un.org/sdgs/indicators/indicators-list/

World Health Organization. (2018). Towards a global action plan for healthy lives and wellbeing for all. Retrieved from International Council of Nurses website: https://www.icn.ch/sites/default/files/inline-files/Global_Action_Plan_Phase_I.PDF 